\title{
Study on Time and Space Characteristics and Environment Optimization of Outdoor Activities of Elderly in Community A case study based on Dezhou city, Shandong province,China
}

\author{
Yi SUN, Tianjin University of Commerce, China \\ Yexuan YANG, Tianjin University of Commerce, China
}

\begin{abstract}
The world's elderly population has soared since the $21^{\text {st }}$ century. In the COVID-19 epidemic in 2020, more than 30\% of deaths worldwide are among the elderly. One of the important reasons for the formation of these diseases is the lack of outdoor exercise, and one of the key influencing factors is the fitness of activity environment. Therefore, it is of theoretical significance and practical value to spatial and temporal environment characteristics of outdoor activities of th elderly. In this study, Dezhou of Shandong province, China, was selected as the research city, where the elderly population ratio was significant. In this study, a questionnaire was compiled, including basic information of the elderly, spatial characteristics of activities, and environmental cognition of community activities, with a total of 30 questions. Data acquisition is conducted both online and offline. In the trial research stage, a total of 100 questionnaires were collected. The statistical results show that: the elderly generally pay attention to outdoor activities and their activity are generally with regularity; activity willingness is restricted by underlying diseases; the activity environment is under weak support; the reconstruction of the activity environment involves distance, facilities, health and epidemic prevention and space innovation.
\end{abstract}

\section{Keywords}

elderly; health; outdoor activities; spatial and temporal characteristics; environmental optimization

\section{Introduction}

China's elderly population is large and growing fast ${ }^{[1]}$, with development of economy and society, the average life expectancy of Chinese people has exceeded the world average level.The National Health Commission,PRC says the average life expectancy in China can reach 77 years.It is not only significantly higher than the world average,but also higher than that of upper-middle income countries. This reflects the sound development trend of China's population and the continuous and obvious improvement of the people's medical care and living standards. Meanwhile,the aging of the population is becoming more and more serious,according to the latest statistics from China's National Bureau of Statistics, the number of people over 60 had reached 254 million,accounting for $18.1 \%$ of the total population by the end of $2018^{[2]}$, and the number of people over 60 is increasing by $3 \%$ a year.It is estimated that by 2025 , the elderly population in China will exceed 300 million,almost one in every 5 people.China's aging population not only has a large base and rapid growth,but also shows the trend of aging and empty-nesters ${ }^{[3]}$. With the deepening of aging,the current society is facing the challenge of effectively improving the living 
environment of the elderly.In the $13^{\text {th }}$ Five-year Plan for the Development of National Undertakings for the Aged and the Construction of the Aged and the Construction of the Old-age care System,the technical secondary school lists "Promoting the construction of livable environment for the aged" as a chapter,emphasizing the construction of livable environment for the aged ${ }^{[4]}$.

Exercise is also an important social activity for retired elderly people,who may feel lonely due to missing their children and other factors.Studies have shown that older people crave information in social interactions,communicate with old friends, make new friends in activities,and form new social networks for emotional venting.Outdoor activities play a very important role in the daily life of the elderly.There are many kinds of leisute and entertainment behaviors in public activity space,and the occurrence ratio pf collective leisure and entertainment behaviors with the participation of many people is much higher than that of individuals.At the same time, this activity will attract other elderly people to watch around,and attract each other among carious activities, which may also trigger other behaviors, making it possible to diversify spatial behaviors ${ }^{[5]}$.And the elderly also have the desire to interact with other groups. They can get psychological satisfaction by interacting with children,middle-aged people and other groups.Planners should consider reintegrating with children's areas to promote intergenerational integration ${ }^{[6]}$.Strengthening the spatial subjectivity,enhancing the spatial experience and improving the safety and comfort can promote the elderly to participate in physical exercise.

In 2020,the COVID-19 epidemic is sweeping the world,with the elderly as a vulnerable group,and the mortality rate is much higher than that of patients under 60 years old. The health problems of elderly have been on the table for discussion again. Health of the elderly has become an important factor affecting the family happiness index.Many elderly people hope to have appropriate rest and recreation space to exercise,such as walking,square dancing,playing chess,waling dogs and so on.They have high expectations for the community environment.

As a province with a large population,Shandong Province has an aging population of 18.95 million. With its moderate level of economic development,Dezhou,located in the northwest of Shandong Province,is a good microcosm of most third-tier cities in China. With the development,the proportion of the elderly population in Dezhou city is also increasing year by year,but the corresponding supporting facilities have not been improved,whtch is particularly prominent in the old communities.This study takes Changhe Street in Dezhou City, Shandong Province as the research object.Through field observation and interviews with communities and residents, this paper attempts to summarize the existing problems of community pension, and puts forward corresponding Suggestions to provide reference for the improvement of living environment and space in the future.

\section{Research methods and survey}

\subsection{The research methods}

\subsubsection{Questionnaire method}

By issuing questionnaires in Changhe street, the basic information, such as activity rules, travel time and travel mode of the elderly, and the elderly's preference for each space, walking distance preference to the activity space and other relevant information were collected, to learn about the elderly in their daily life sports lectures and what are the inconvenience, and put forward solutions.

\subsubsection{Literature study method}

Through the statistical yearbook, government website, etc., collect the dezhou city elderly outdoor activities related written materials, did a summary.Search "elderly", "outdoor activities", "sports", "sports and health" and other keywords through CNKI, and consult relevant domestic and foreign journals, 
academic works, professional data, papers and so on in recent years.After a comprehensive understanding of the research background and current situation, the collected literature was repeatedly read and further studied.

\subsubsection{Interview method}

Making visits and surveys to communities and pension service institutions, interview relevant staff, managers, service personnel and the elderly, obtain first-hand information, and understand the time and space characteristics of the current outdoor activities of the elderly, as well as the problems and inconvenience they encounter when traveling.

\subsubsection{Field observation method}

Combine the knowledge in books with the actual situation of outdoor activities of the elderly, and sum up all kinds of problems encountered by the elderly population during exercise.

\subsection{Field survey}

\subsubsection{Survey area selection}

Dezhou is located in the northwest of Shandong province, with a total area of 10,356 square kilometers, bordering the Beijing-Tianjin-Hebei region in the north and jinan, capital of neighboring Shandong province in the south.Dezhou is one of the cities that entered the aging population earlier. It entered the aging population in 1995. The large number and rapid growth of the elderly population have brought huge challenges to the economic and social development of Dezhou. In recent years, with the support of national policies and other aspects, riding the express train of the integration of Beijing-Tianjin-Hebei, Dezhou's economy has developed rapidly, but at the same time, the aging of its population is also accelerating. While ensuring economic development, how to make it more convenient for the elderly to do outdoor activities, improve their living standards and increase their happiness index is our research topic.

Based on the spatial distribution of the movement and the number of the elderly population around, the investigation scope will be determined in Changhe Street of Dezhou City. Changhe Sub-district office has jurisdiction over an area of 16.8 square kilometers, with 14 administrative villages and 9 communities with a population of 48,297 (2010). This survey took Changhe Park as the center and surveyed the surrounding communities. 

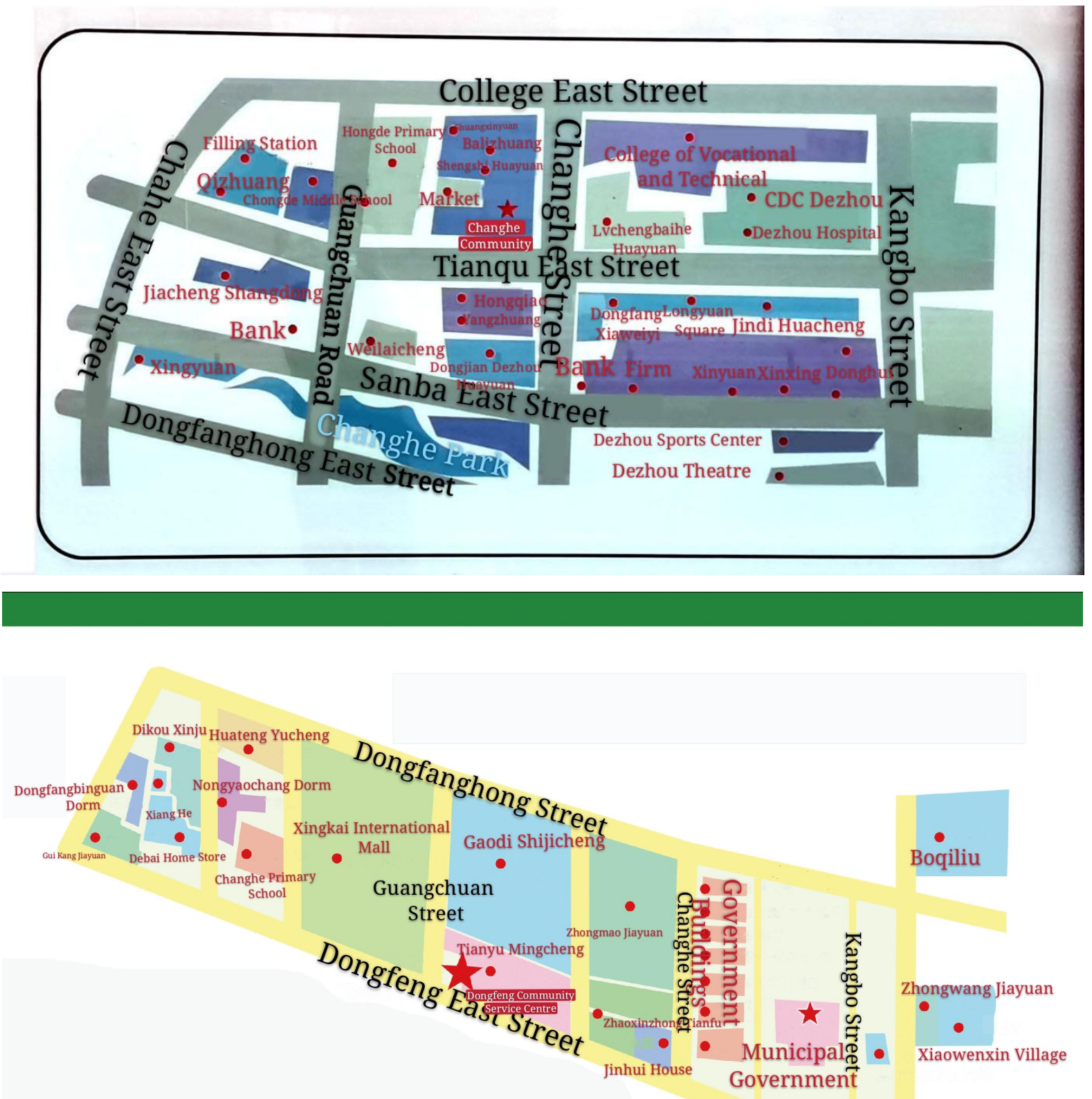

\subsubsection{Survey questionnaire and interview overview}

From May 13, 2020 to May 20, the research team conducted an 8-day field survey, including questionnaires and interviews. The questionnaire includes:

(1) Basic questions: age, sex, area of residence, occupation before retirement, type of house to live in, whether there is elevator in the building.

(2) Exercise awareness: the importance of exercise, whether to monitor their exercise status, what kind of exercise mode they prefer, and whether it is necessary to build a special activity space for the elderly.

(3) Sports related issues: the way of travel, can accept activity space, distances from the address to an activity of time, whether to have regular exercise habit, whether suffering from diseases affecting sports, 
community is regularly organize activities of old people together, the present living area can provide convenient exercise environment and so on.

The interview includes:

(1) What facilities do you think are needed in the activity space? Is it necessary to carry out regular elimination work in public places in low-risk areas for COVID-19?

(2) What improvements do you think can be made to the environment of the sports venues around you?

In order to ensure that the survey content is practical and effective, the respondents of this questionnaire are all elderly people over 60 years old, randomly selected in the community for questionnaire and interview, so as to reflect the real problems and needs of the elderly. The number of questionnaires collected this time was 100 , with 15 interviewees.

\section{The activity characteristics of the elderly and the current situation of activity space}

\subsection{Outdoor activities of the elderly community features}

According to the results of the questionnaire survey and the conclusion of the interview, we generally summarized the following characteristics.

\subsubsection{Activity time}

According to the survey, most of the elderly choose to go out for exercise at about 3 p.m. and go home at about 5 p.m. This is a relatively easy time for the elderly, who don't need to cook. And 3-5 o'clock outdoor sunshine is conducive to the elderly calcium supplements, improve the health of the body's bones.

(1) Travel time characteristics

The research objects selected by the group are all elderly people over 60 years old who have retired. Therefore, working days and rest days have little impact on most of the research objects. According to the questionnaire results, the group obtains the following data:

\begin{tabular}{|c|c|c|c|c|}
\hline Travel time & Before 7 a.m. & 7 a.m. to 12 p.m. 12 p.m. to 17 p.m. & After 17 p.m. \\
\hline percentage & $23 \%$ & $17 \%$ & $35 \%$ & $25 \%$ \\
\hline
\end{tabular}

It can be seen from the data in the table that most elderly people prefer to go out for exercise in the morning when the air is fresh, in the afternoon when the sun is full and after dinner when they are free.

(2) Activity duration characteristics

According to the analysis of the questionnaire results, the following data are obtained.

\begin{tabular}{|c|c|c|c|c|} 
The movement time & Within an hour & 1 to 2 hours & 2 to 3 hours & More than 3 hours \\
\hline percentage & $35 \%$ & $39 \%$ & $20 \%$ & $6 \%$ \\
\hline
\end{tabular}

According to the data, the exercise time of most old people is not more than 2 hours. The reason is mainly physical strength, and it is not suitable to take exercise for a long time due to diseases and other reasons.

\subsubsection{Activity space aspect}


Elderly people in Changhe community are more likely to choose Changhe Park as a place for exercise. Elderly people with relatively weak mobility are more likely to do exercise in the community or near the residential area, which requires higher related supporting facilities within the residential area. However, most of the exercise equipment in the community does not conform to the exercise characteristics of the elderly, unable to provide a convenient and safe exercise environment for the elderly.

Most of the elderly over the age of 65 suffer from certain diseases, which more or less affect their sports health. Therefore, the vast majority of the elderly choose a more moderate way of exercise, such as walking, using daily fitness equipment and so on. The elderly women who tend to square dancing are mostly young.

Nearly half of the elderly have to help their children take care of their grandchildren in their daily lives, so some of them choose to take exercise while taking their children out. These older people are more likely to exercise in more fixed places, such as fitness equipment.

(1) Activity space requirements

\begin{tabular}{|c|c|c|c|c|c|}
\hline $\begin{array}{l}\text { Hardware } \\
\text { requirements }\end{array}$ & $\begin{array}{c}\text { Shading and rain } \\
\text { shelter }\end{array}$ & $\begin{array}{l}\text { Public } \\
\text { toilet }\end{array}$ & garbage & seats & $\begin{array}{l}\text { Fitness } \\
\text { equipment }\end{array}$ \\
\hline percentage & $81 \%$ & $68 \%$ & $61 \%$ & $94 \%$ & $65 \%$ \\
\hline $\begin{array}{l}\text { Hardware } \\
\text { requirements }\end{array}$ & lighting & vegetation & $\begin{array}{l}\text { Recreational facilities for } \\
\text { children }\end{array}$ & $\begin{array}{l}\text { Barrier-free } \\
\text { design }\end{array}$ & pond \\
\hline percentage & $45 \%$ & $39 \%$ & $16 \%$ & $36 \%$ & $9 \%$ \\
\hline
\end{tabular}

Hardware requirements for activity space mainly focus on seats, shading and rain shelter facilities, public toilets, lighting facilities, etc.

(2) Activity location distance requirement

\begin{tabular}{|c|c|c|c|c|}
\hline \multirow{2}{*}{ Distance } & $\begin{array}{c}\text { As close as } \\
\text { possible }\end{array}$ & Less than $0.5 \mathrm{~km}$ & $0.5 \mathrm{~km}-1 \mathrm{~km}$ & More than $1 \mathrm{~km}$ \\
\hline percentage & $\mathbf{5 2 \%}$ & $\mathbf{2 6 \%}$ & $\mathbf{1 9 \%}$ & $3 \%$ \\
\hline
\end{tabular}

The elderly are more likely to exercise in locations closest to their home address.

\subsection{Current situation of activity space}

During the investigation, I saw many old people go to Changhe Park for exercise by bike for half an hour, which is far from home and inconvenient. The reason is that the community environment is not good, it is difficult to provide a better exercise environment. Combined with the questionnaire, we found that for the elderly, most of the activity space has the following problems:

(1) Traffic safety in the activity space has hidden dangers. There are many vehicles in the community, so it is not convenient to take exercise, and the safety problem is prominent. Therefore, the elderly choose Changhe Park for exercise.Nowadays, private cars are becoming more and more popular. Some families even have two or more motor vehicles. In some communities, one parking space per family is obviously not enough, so motor vehicles inevitably take up other public spaces and activity spaces are crowded. At the same time, most of the residential ground is not car-free management, the elderly, children and other people with leg trouble safety is difficult to ensure.

(2) Little space for activities and incomplete exercise facilities. The environment in the community is poor, and the fitness equipment is old, so the maintenance can't keep up with it. The number of activity 
facilities is small and cannot meet the needs of the elderly, which is also one reason why the elderly choose parks far away for exercise.

(3) There is a lack of supporting facilities associated with the event. In particular, lack of shade, rain shelter, rest, toilet and other activities supporting facilities. Exposure to the sun for a long time in summer is harmful to health. At the same time, more rain, shelter facilities are not complete, affecting the elderly to go out. Fewer seats, the elderly legs and feet inconvenience, need to rest, but seats in short supply. According to the survey, most elderly people would like to have more public restrooms in their communities, and similar problems have been found in many communities visited: the community has a good environment with high greening rate. However, without public toilets, the elderly and children cannot exercise outside for a long time.

(4) There is a lack of diversity and inclusiveness of activity space, especially children's entertainment space and pet space. A considerable number of the elderly have the task of taking care of their grandchildren, but the children's slide, swing and other facilities containing children's activities space are less, which brings inconvenience to the elderly to take care of children. In addition, there is a lack of pet space. Many elderly people choose to keep pets as their spiritual sustenance in order to relieve their inner feelings of longing. However, China's domestic tolerance for pets needs to be improved. Many public places explicitly prohibit pets from entering, and there is no device to dispose of pet feces in the community, which puts the elderly pet owners in an awkward situation.

(5) Barrier-free facilities are not perfect. Most communities do not provide easy access. Some elderly people suffer from leg diseases and find it difficult to stand and walk for a long time. Therefore, the wheelchair and other walking equipment is necessary for him to go out. However, the lack of barrier-free facilities makes it more inconvenient for these old people to travel, which in turn leads to their reluctance to go out for exercise, which has a negative impact on their physical health.

(6) Regular elimination work to be improved. Prior to the COVID-19 outbreak, there had been very little eradication in public places, and the community generally paid little attention to it, so in the early days of the outbreak, the transmission of the virus was not well cut off, and there was widespread fear.

\section{Improvement measures}

According to the above questions, the team members carried out statistical analysis and came up with the following improvement methods for reference.

(1) Improve traffic safety. In order to ensure the safety of pedestrians, it is suggested to design the human-car branch system. The physical decline of the elderly is a fact, so it is unavoidable for the elderly to dodge in the face of motor vehicles. The human-car branch system can greatly reduce the probability of injuries of the elderly due to such reasons, and also improve the continuity of walking and the smoothness of the passage space.

(2) Expand the activity space area and add exercise facilities. Maintain the fitness equipment in the community regularly to reduce the possibility of accidents and provide a convenient exercise environment for the elderly.

(3) Add supporting facilities related to the event. In particular, increase rest facilities, public toilets, shade, shelter from the rain facilities. During a visit, team members found that most communities did not provide special seats for the elderly. Many elderly people suffer from all kinds of leg diseases. They will feel uncomfortable when walking or standing for a long time, so they need a seat to rest. But most communities are deficient in this aspect. In the future, seats and benches can be added to provide adequate rest space for the elderly and children. In the park and other special exercise space, the setting of public toilets is relatively perfect, but in the community and around the community, the setting of 
public toilets is relatively deficient, which leads to the elderly exercise in the neighborhood exercise time is shortened, travel is very inconvenient. Future planning should pay attention to similar public restrooms. At present, the park and other public places have set corresponding facilities for shade and rain shelter, but they are not enough to meet people's needs. In the planning process, the number of facilities can be appropriately increased.

(4) Increase spatial diversity. Children's entertainment facilities can be installed in the space, pets can be added to exercise in the park, or specially used for walking the dog pet space, the space can be further divided to achieve the purpose of composite utilization. In the future, community staff should visit the community activity space regularly to check and repair the damaged fitness equipment, so as to avoid accidents in the use of the elderly and children and harm their health. At the same time, they should also maintain the sanitation of the pet space to avoid environmental pollution.

(5) Improve barrier-free design. During the research, it was found that most of the communities had no special barrier-free design, so some elderly people with leg difficulties could hardly go out alone, and they could not go out when no one was at home, and they needed at least a prime of life to help them go out. It largely limits the amount of time the elderly have to go out for exercise. Future community planning should improve the barrier-free design to facilitate the elderly to go out.

(6) The activity space should be sterilized regularly. The epidemic in China is now largely stable, but there are still occasional small outbreaks. Experts say the virus is likely to coexist with humans for a long time, so there is still a chance of another winter outbreak. So in public places, especially places where susceptible people gather, regular disinfection and sterilization work is particularly important. It is hoped that community workers can organize regular elimination work to try to stop the transmission of the virus. During this study, we also learned that the majority of the elderly support regular disinfection in public places, and we can feel the importance people attach to the virus.

\section{Future expectations}

Due to the haste, the number of samples collected is relatively small and the regions are relatively concentrated, which may lack universality. Therefore, more attention will be paid in future studies. Every family has an old man, and everyone will grow old. We hope that the whole society can pay more attention to the living environment and exercise space of the elderly, and provide them with more safe and comfortable activity space. At the same time, I hope this survey can provide relevant ideas for relevant departments and provide more convenient exercise environment for the elderly.

\section{References}

Please use the "Harvard style" of references (in Mendeley - Harvard Reference style 1). Use approximately 20 to 60 references.

Book: Author surname(s), initials(s), (Year published) Title. Edition. Place of publication: Publisher.

Mitchell, J.A. and Thomson, M. (2017) A guide to citation. 3rd edn. London: London Publishings. 
Edited Book: Editor surname(s), initial(s). (eds.) (Year Published). Title. Edition. Place of publication: publisher.

William, S.T. (eds.) (2015) Referencing: a guide to citation rules. New York: My Publisher

Chapter in an Edited Book: Editor surname(s), initial(s). (Year Published). 'Title of chapter' in editor(s) surname(s), initials(s) (eds.) Title of book. Edition. Place of publication: publisher, page numbers.

Troy B.N. (2015) 'Harvard citation rules' in Williams, S.T. (ed.) A guide to citation rules. New York: NY Publishers, pp. 34-89.

E-Book: Author surname(s), initial(s). (Year Published). Title. Edition. E-book format [e-book reader]. Available at URL or DOI (Accessed: day month year)

Mitchell, J.A., Thomson, M. and Coyne, R.P. (2017) A guide to citation. E-book library [online]. Available at: https://www.mendeley.com/reference-management/reference-manager (Accessed: 10 September 2016)

Journal Article: Author surname(s), initial(s). (Year) 'Title of article', Title of journal, volume (issue), page numbers.

Mitchell, J.A. 'How citation changed the research world', The Mendeley, 62(9), p70-81.

Online Journal: Author surname(s), initial(s). (Year) 'Title of article', Title of journal, volume (issue) [online]. Available at: URL or DOI (Accessed: day month year)

Mitchell, J.A. 'How citation changed the research world', The Mendeley, 62(9) [online]. Available at: https://www.mendeley.com/reference-management/reference-manager (Accessed: 15 November 2016)

Newspaper Article: Author surname(s), initial(s). (Year) 'Article Title', Newspaper Title (edition), day month, page number(s).

Mitchell, J.A. (2017) 'Changes to citation formats shake the research world', The Mendeley Telegraph (Weekend edition), 6 July, pp.9-12.

Online Newspaper: Author surname(s), initial(s). (Year) 'Article Title', Newspaper Title (edition), day month [online]. Available at: URL or DOI (Accessed: day month year) 